\title{
A giant carotid aneurysm preventing correct swallowing
}
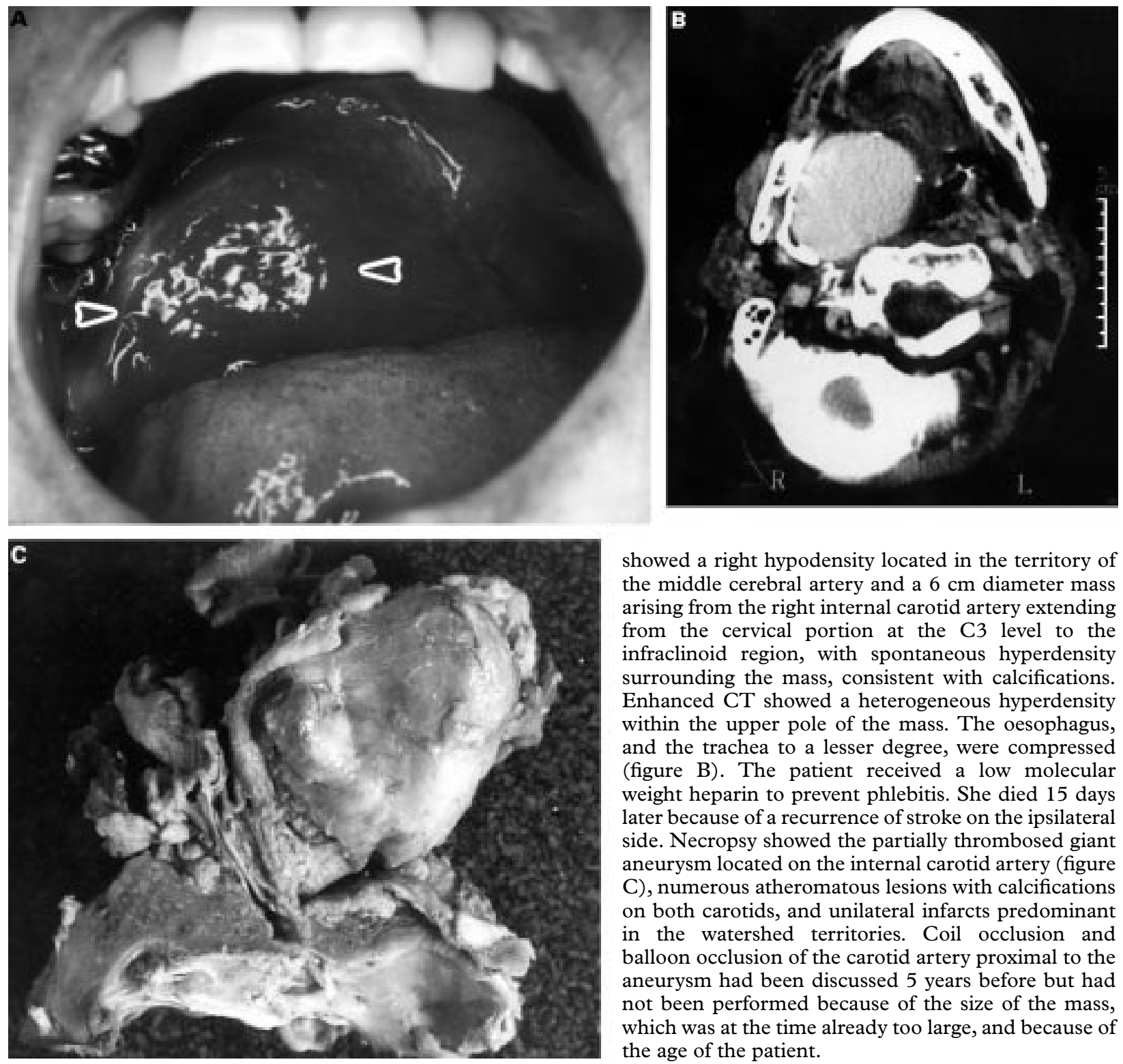

showed a right hypodensity located in the territory of the middle cerebral artery and a $6 \mathrm{~cm}$ diameter mass arising from the right internal carotid artery extending from the cervical portion at the C3 level to the infraclinoid region, with spontaneous hyperdensity surrounding the mass, consistent with calcifications. Enhanced CT showed a heterogeneous hyperdensity within the upper pole of the mass. The oesophagus, and the trachea to a lesser degree, were compressed (figure B). The patient received a low molecular weight heparin to prevent phlebitis. She died 15 days later because of a recurrence of stroke on the ipsilateral side. Necropsy showed the partially thrombosed giant aneurysm located on the internal carotid artery (figure C), numerous atheromatous lesions with calcifications on both carotids, and unilateral infarcts predominant in the watershed territories. Coil occlusion and balloon occlusion of the carotid artery proximal to the aneurysm had been discussed 5 years before but had not been performed because of the size of the mass, which was at the time already too large, and because of the age of the patient.

Giant aneurysms of the internal carotid artery are rare. Complications are not related to rupture but to cerebral emboli. A surgical approach should be used to exclude the aneurysm from the cerebral circulation either by coil occlusion of the aneurysm, balloon internal carotid artery occlusion, or internal carotid artery ligation. We report on an 87 year old woman who was referred with a sudden onset of left hemiplegia. She had no vascular risk factor, in particular no hypertension. There was no traumatic or infectious event in her medical past. The patient had been followed up in another hospital for 5 years for progressive worsening dysphagia and dysphonia. At examination, a pulsatile mass was found when the patient opened her mouth, emerging from the right posterior pharyngeal wall (figure A). Brain CT
N KUBIS

M HAGUENAU F WOIMANT

Department of Neurology, Hôpital Lariboisière, 2 rue Ambroise Paré, 75010 Paris, France

D VON LANGSDORFF J MIKOL

Department of Pathology

B DELFINER

Department of Neurology, Fondation Ophtalmologique de Rothschild, 25-29 rue Manin, 75940 Paris cédex 19, France

Correspondence to: Dr France Woimant

woimant@1rb.ap-hop-paris.fr 